Geisa Martins Faustino

\title{
Um Método Baseado em Mineração de Grafos para Segmentação e Contagem de Clusters de Máximos Locais em Imagens Digitais
}

Tese apresentada como requisito parcial para obtenção do grau de Doutor pelo Programa de Pós-graduação em Informática do Departamento de Informática do Centro Técnico Científico da PUC-Rio

Orientador

Prof. Marcelo Gattass

Co-Orientador: Prof. Carlos José Pereira de Lucena 


\section{Geisa Martins Faustino}

\section{Um Método Baseado em Mineração de Grafos para Segmentação e Contagem de Clusters de Máximos Locais em Imagens Digitais}

Tese apresentada como requisito parcial para obtenção do grau de Doutor pelo Programa de Pós-graduação em Informática do Departamento de Informática do Centro Técnico Científico da PUC-Rio. Aprovada pela Comissão Examinadora abaixo assinada.

Prof. Marcelo Gattass

Orientador

Departamento de Informática - PUC-Rio

Prof. Carlos José Pereira de Lucena

Co-Orientador

Departamento de Informática - PUC-Rio

Prof. Waldemar Celes

Departamento de Informática - PUC-Rio

Prof. Alberto Barbosa Raposo Departamento de Informática - PUC-Rio

Prof. Aristófanes Corrêa Silva Departamento de Engenharia de Eletricidade - UFMA

Prof. Stevens Kastrup Rehen Universidade Federal do Rio de Janeiro - UFRJ

Prof. José Eugenio Leal

Coordenador Setorial do

Centro Técnico Científico - PUC-Rio 
Todos os direitos reservados. É proibida a reprodução total ou parcial do trabalho sem autorização da universidade, do autor e do orientador.

\section{Geisa Martins Faustino}

Graduou-se em Bacharel em Matemática pela Universidade do Estado do Rio de Janeiro no ano de 2003. Tornou-se mestre em Matemática com ênfase em Computação Gráfica pelo IMPA Instituto Nacional de Matemática Pura e Aplicada em 2005.

Ficha Catalográfica

Faustino, Geisa Martins

Um Método Baseado em Mineração de Grafos para Segmentação e Contagem de Clusters de Máximos Locais em Imagens Digitais/ Geisa Martins Faustino; orientador: Marcelo Gattass; co-orientador: Carlos José Pereira de Lucena. - 2011.

79 f.: il. (color); $29,7 \mathrm{~cm}$

Tese (doutorado) - Pontifícia Universidade Católica do Rio de Janeiro, Departamento de Informática, 2011.

Inclui bibliogrfia.

1. Informática - Teses. I. Gattass, Marcelo. II. Lucena, Carlos J. P. de. III. Pontifícia Universidade Católica do Rio de Janeiro. Departamento de Informática. IV. Título. 


\section{Agradecimentos}

Agradeço primeiramente a Deus pelas oportunidades dadas a mim ao longo de minha vida. Ele, que em sua infinita bondade colocou em meu caminho pessoas maravilhosas, que nos momentos tumultuados - naturais no caminho - não me deixaram cair em abatimento.

À minha família, especialmente a minha mãe, por todo apoio, carinho, dedicação, incentivo e paciência, não só durante o período do doutorado, mas em TODOS os momentos da minha vida.

Aos amigos que sempre estiveram presente, mesmo que de maneira virtual, me apoiando, incentivando e também me distraindo quando estava exausta de tanto trabalhar.

Ao meu namorado João Vitor, e aos amigos Myriam e Vitor pelo apoio, incentivo, paciência, compreensão e carinho durante a etapa final deste período.

À todos aqueles que foram meus professores.

Aos meus orientadores, Marcelo Gattass e Carlos J. P. de Lucena, pela dedicação, incentivo, críticas, suporte, ensinamentos e principalmente pela segurança na orientação.

Ao professor e amigo Aristófanes C. Silva por ter confiado e acreditado em mim no início e nos momentos mais difíceis do doutorado. Pelas reuniões/discussões, reais e virtuais (em sua maioria), às vezes curtas, mas todas sempre muito proveitosas. Pelo incentivo, críticas, ensinamentos, pela segurança na orientação e também paciência.

Ao professor Stevens Rehen e sua equipe, pelo suporte biomédico e imagens fornecidas.

Aos meus chefes no Tecgraf, Leonardo e Ivan, pela compreensão e apoio.

À amiga e professora Maria Emília Loureto (language instructor) pelas aulas de inglês, fundamentais para o melhoramento das minhas habilidades de leitura, escrita e conversação na língua inglesa e aprovação no exame de proficiência de língua estrangeira garantindo a minha continuidade no doutorado. Agradeço também pelas traduções, correções, apoio, incentivo e carinho.

À Carolina Alfaro, pelas correções e dicas em meus artigos.

À CAPES e CNPq que me proporcionaram bolsa de fomento, fundamental para a realização deste trabalho.

Muito obrigado a todos. 


\section{Resumo}

Faustino, Geisa Martins; Gattass, Marcelo; Lucena, Carlos J. P. de.

Um Método Baseado em Mineração de Grafos para Segmentação e Contagem de Clusters de Máximos Locais em Imagens Digitais.

Rio de Janeiro, 2011. 79p. Tese de Doutorado — Departamento de Informática, Pontifícia Universidade Católica do Rio de Janeiro.

Uma imagem monocromática pode ser interpretada como uma superfície topológica e desta forma objetos de interesse podem aparecer como picos (sharp mountains), domos (smooth hills) ou vales (V-or U-shaped). Um domo geralmente contém vários pontos de máximo locais em seu topo. Logo, fica bem caracterizado por um cluster de máximos locais. Segmentar individualmente objetos em imagens onde estes aparecem parcialmente sobrepostos ou fortemente agrupados é um problema que métodos clássicos de segmentação podem não solucionar adequadamente. Outro problema é contar objetos semelhantes em imagens previamente segmentadas. Esta tarefa, quando executada manualmente, devido ao cansaço visual exige um grande esforço humano. É tediosa, demorada, além de gerar resultados subjetivos. O presente trabalho propõe um novo método para segmentação e contagem de clusters de máximos locais em uma imagem digital através de uma abordagem baseada em grafos. Utilizando a informação de luminância, a imagem é representada por um grafo de adjacências e um algoritmo de mineração é utilizado para segmentar os clusters. Por fim, de acordo com características da imagem, um algoritmo de clusterização pode ser incorporado ao processo para melhorar o resultado final. A contagem dos objetos é um resultado direto do algoritmo de mineração e de clusterização, quando este último é aplicado. O método proposto é tolerante a variações no tamanho e forma dos objetos e é facilmente parametrizado para lidar com diferentes grupos de imagens provenientes de objetos distintos. Testes executados em uma base de dados com 262 imagens, composta de fotos de objetos (grupo 1) e de células tronco embrionárias em imagens de microscopia fluorescente (grupo 2), atestam a eficiência e qualidade do método desenvolvido no que diz respeito a segmentação e a contagem. Os resultados gerados para as imagens do grupo 1 foram validados pela autora e os do grupo 2 pelos biólogos do Instituto de Ciências Biomédicas da Universidade Federal do Rio de Janeiro. Para estas imagens foram obtidas uma F-measure média de $85,33 \%$ e $90,88 \%$, respectivamente. Por fim, um estudo comparativo com o algoritmo clássico de watershed foi realizado. Este alcançou uma F-measure média de 74,02\% e 78, 28\% para os grupos 1 e 2, respectivamente, contra $85,33 \%$ e $91,60 \%$ obtido pelo método proposto.

\section{Palavras-chave}

Segmentação e contagem de clusters de máximos locais. Representação de imagem baseada em grafo. Mineração de grafo. Clusterização de grafo. 


\section{Abstract}

Faustino, Geisa Martins; Gattass, Marcelo (Advisor) ; Lucena, Carlos J. P. de (Co-Advisor) . A Graph-mining Based Method for Segmentation and Counting of Local Maximum Clusters in Digital Images. Rio de Janeiro, 2011. 79p. DSc Thesis - Department of Informática, Pontifícia Universidade Católica do Rio de Janeiro.

A grayscale image can be viewed as a topological surface and this way, objects of interests may appear as peaks (sharp mountains), domes (smooth hills) or valleys (V- or U-shaped). Generally, the dome top presents more than one local maximum. Thus, it can be characterized by a local maximum cluster. Segmenting objects individually in images where they appear partially or totally fused is a problem which frequently may not be solved by a watershed segmentation or a basic morphological processing of images. Other issue is counting similar objects in images segmented beforehand. Counting them manually is a tedious and time-consuming task, and its subjective nature can lead to a wide variation in the results. This work presents a new method for segmenting and counting of local maximum clusters in digital images through a graph-based approach. Using the luminance information, the image is represented by a region adjacency graph and a graph-mining algorithm is applied to segment the clusters. Finally, according to image characteristics, a graph-clustering algorithm can be added to the process to improve the final result. The object counting step is a direct result from the mining algorithm and the clustering algorithm, when the latter is applied. The proposed method is tolerant to variations in object size and shape and can easily be parameterized to handle different image groups resulting from distinct objects. Tests made on a database with 262 images, composed of photographs of objects (group 1) and embryonic stem cells under fluorescence microscopy images (group 2), attest the effectiveness and quality of the proposed method as for segmentation and counting purpose. The images form group 1 processed by our method were checked by the author and those ones from group 2 by the specialists from the Institute of Biomedical Sciences at UFRJ. For these images we obtained an average F-measure of $85.33 \%$ and $90.88 \%$, respectively. Finally, a comparative study with the widely used watershed algorithm was done. The watershed achieved an average F-measure of $74.02 \%$ e $78.28 \%$ for groups 1 and 2 , respectively, against $85.33 \%$ e $91.60 \%$ obtained by our method.

\section{Keywords}

Segmentation and counting of local maximum clusters. Graph-based image representation. Graph mining. Graph clustering. 


\section{Sumário}

1 Introdução $\quad 15$

1.1 Contribuições 18

1.2 Trabalhos Relacionados 19

1.3 Organização do Trabalho 22

2 Algoritmo para Segmentação e Contagem de Clusters de Máximos Locais

2.1 Pré-processamento 25

2.2 Partição do Histograma 26

2.3 Detecção das Componentes Conectadas 28

2.4 Construção do Grafo 29

2.5 Processo de Mineração do Grafo 31

2.6 Algoritmo para Clusterização do Grafo 36

3 Resultados Experimentais e Discussão 4

3.1 Experimento 1: segmentação e contagem de objetos em fotos 42

3.2 Experimento 2: detecção e contagem de células tronco embrionárias em imagem de microscopia fluorescente 49

4 Conclusão $\quad 62$

4.1 Trabalhos Futuros $\quad 65$

Referências Bibliográficas $\quad 72$ 


\section{Lista de figuras}

1.1 Exemplo de imagens não triviais de serem segmentadas.

1.2 Exemplo de objetos que são representados por CML quando a imagem é interpretada como uma superfície topológica: a esquerda a imagem capturada e a direita a visualização 3D correspondente.

2.1 Visão geral do método proposto: cada passo é representado por uma caixa. Os ítens em cinza (clusterização do grafo e segmentação do fundo) representam os passos opcionais.

2.2 Curvas de nível e partição do histograma para a imagem apresentada na Figura 1.2(a) para dois valores de $\varepsilon$ : (a) e (b) apresentam os resultados para $\varepsilon=64$ e; (c) e (d) para $\varepsilon=32$, respectivamente.

2.3 Resultado do filtro Gaussiano: (a) imagem de entrada; (b) e (c) informação de luminância e superfície topológica correspondente; (d) e (e) resultado do filtro Gaussiano sobre a imagem e sobre a superfície, respectivamente.

2.4 Resultado da etapa de segmentação do fundo e exemplos de quando ela deve ou não ser aplicada: (a) resultado desta etapa para imagem apresentada na Figura 2.3(a); (b) e (c) imagem de microscopia fluorescente e respectivo resultado da segmentação do fundo; e (d) imagem de miçangas, a qual não possui fundo.

2.5 Partição do histograma e imagens binárias correspondentes para a imagem apresentada na Figura 2.3(a).

2.6 Imagens binárias representando cada intervalo da partição do histograma apresentado na Figuras 2.2(b) e 2.2(d), respectivamente. As setas na cor vermelha indicam as mudanças decorrentes de valores diferentes para o tamanho do intervalo

2.7 Componentes conectadas com seus respectivos identificadores e parte da matriz $M$ para a imagem apresentada na Figura 1.2(a).

2.8 Matriz $M$ e representação da imagem baseada em grafo para a imagem da Figura 1.2(a): (a) pequena parte da matriz $M$; (b) componentes detectadas com respectivos identificadores; e (c) RAG correspondente.

2.9 Componentes conectadas e representação da imagem baseada em grafo para a imagem da Figura 2.3(a).

2.10 Exemplo de representação da imagem baseada em grafo para uma imagem natural. 
2.11 Resultado obtido com o algoritmo de mineração para a imagem da Figura 2.3(a): (a) imagem de entrada; (b) representação da imagem baseada em grafo; (c) caminhos simples encontrados; e (d) resultado do algoritmo sobre a imagem.

2.12 Resultado do algoritmo de mineração de grafo: (a) imagem de entrada; (b) regiões conectadas; (c) objetos identificados; (d) caminhos simples encontrados durante a etapa de mineração do grafo; e (e) representação da imagem de entrada baseada em grafo.

2.13 Resultado obtido com o algoritmo de mineração e resultados das etapas 1 e 2 do algoritmo de clusterização.

2.14 Resultados das etapas 3, 4 e 5 do algoritmo de clusterização.

3.1 Fotos de objetos reais dividas em sete grupos: (a) fotos de miçangas (contas); (b) fotos de pérolas sintéticas; de (c) a (g) fotos de miçangas (contas); de (h) a (l) fotos de pérolas sintéticas; $(m)$ e $(n)$ fotos de doces; $(0)$ fotos de pedra; de (p) à (r) fotos de grãos de feijão; (s) fotos de grãos de café e; (t) fotos de uvas.

3.2 Resultados obtidos com o método desenvolvido e o algoritmo de watershed em fotos de objetos.

3.3 Resultados obtidos com o método desenvolvido e o algoritmo de watershed em fotos de objetos.

3.4 Comparação entre o método desenvolvido e o algoritmo de watershed para fotos de objetos. Note que o método proposto obteve melhores resultados para a maioria das imagens.

3.5 Exemplo de imagens de células tronco embrionárias: (a) EB cryosection com aumento de $40 \times$; (b) e (c) imagens de migração celular de corpos embrióides com aumento de $40 \times$ e $20 \times$, respectivamente; (d) e (e) imagens de colônias de células mES sobre MEF com aumento de $40 \times$ e $20 \times$, respectivamente; e (f) neuroesferas.

3.6 Resultados obtidos com o método proposto: (a) e (b) mostram imagens de EB cryosections com um nível de ruído aceitável (grupo 1) e presença de forte ruído (grupo 2), respectivamente; (c) e (d) apresentam imagens de migração de EB com aumento de $40 \times$ e $20 \times$ (grupos 3 e 4), respectivamente; (e) e (f) mostram imagens de colônias de mES sobre MEF com aumento de $20 \times$ e $10 \times$ (grupos 5 e 6 ), respectivamente; e (g) apresenta uma imagem de neuroesfera.

3.7 Embryonic Stem Cell Counter software (ESCC), aplicativo gratuito desenvolvido para detectar e contar automaticamente células tronco embrionárias em imagens de microscopia fluorescente. 
3.8 Resultados obtidos com o método proposto e com o algoritmo de watershed: (a) e (d) comparam os resultados para imagens de EB cryosection; (b) e (e) para imagens de migração de EB com aumento de $40 \times$; e (c) e (f) para imagens de migração de EB com aumento de $20 \times$.Os pontos em vermelho e em azul assinalam as células que foram detectadas. 59

3.9 Resultados obtidos com o método proposto e com o algoritmo de watershed: (a) e (d) para imagens de colônias de células mES sobre MEF com aumento de $20 \times$; (b) e (e) para imagens de colônias de mES sobre MEF com aumento de $10 \times ;$ e (c) e (f) para imagens de neuroesferas. Os pontos em vermelho e em azul assinalam as células que foram detectadas. 60

3.10 Comparação entre o método proposto e a algoritmo de watershed no que diz respeito à imagens de células tronco embrionárias. Todas as imagens foram analisadas e avaliadas visualmente pela autora baseada em exemplos de contagem correta fornecidos pelos biólogos do Instituto de Ciências Biomédicas da UFRJ.

4.1 Resultados preliminares obtidos com o método proposto para imagens do tipo IKONOS [42]. Os pontos na cor vermelha indicam as árvores segmentadas.

4.2 Resultados preliminares obtidos com o método apresentado neste trabalho para imagens bidimensionais de electrophoresis gels [81]. Os pontos na cor vermelha indicam os spots segmentados.

4.3 Resultados preliminares obtidos com o método apresentado neste trabalho para imagens de solitary odontogenic keratocyst lining [48]. Os pontos vermelhos representam os cistos segmentados.

4.4 Resultados preliminares obtidos com o método apresentado neste trabalho para imagens de micrografias eletrônicas muscular [79]. Os pontos vermelhos indicam os filamentos de miosina detectados.

4.5 Exemplo de imagens de células tronco "coloridas"com três marcadores celulares diferentes: (a) marcador DAPI: marca todas as células; (b) $\beta$ - III tubulina - marcador específico para neurônios; e (c) GFAP - marcador glial.

4.6 Estrutura interna do olho humano.

4.7 Resultados preliminares para detecção da primeira imagem de Purkinje. Note que além do brilho do olho, o método detectou outros pontos brilhantes, os quais devem ser eliminados em um passo adicional. 


\section{Lista de tabelas}

3.1 Resultados obtidos e respectivos parâmetros utilizados para as imagens de cada grupo. Valores em branco indicam que o respectivo passo não foi aplicado. A primeira coluna (G.) indica o Grupo de imagens e a última linha apresenta a média aritmética para precision, recall e F-measure obtidos pelo método proposto e pelo algoritmo de watershed.

3.2 Base de dados dividida em 7 grupos de imagens e os respectivos valores utilizados para os parâmetros de entrada: valor para o raio do filtro Gaussiano $(\sigma)$, o parâmetro $(x)$ utilizado para calcular o threshold, tamanho do intervalo $(\varepsilon)$ e metade do valor médio do diâmetro da célula $(\lambda)$. A segunda coluna mostra a quantidade de imagens para cada um dos grupos.

3.3 Resultados obtidos com o método proposto para imagens de células tronco embrionárias. Todos os números são valores médios calculado sobre as imagens de cada grupo. A última coluna mostra quando o sexto passo (clusterização do grafo) do algoritmo foi utilizado. A última linha apresenta o valor médio para precision, recall e F-measure sobre todas as imagens.

3.4 Conjuntos representando os grupos principais. A primeira coluna indica os conjuntos e a segunda os respectivos grupos que eles representam. A terceira coluna apresenta o número e o tipo de imagem.

3.5 Comparação entre método proposto, com e sem o passo 6 (clusterização do grafo), e o algoritmo de watershed [54]. A primeira coluna indica os conjuntos de imagens e as demais apresentam os resultados obtidos pelo método proposto e pelo watershed. Todos os números são valores médios obtidos sobre todas as imagens do respectivo conjunto. 


\section{Lista de Artigos Publicados}

A seguir, uma lista com os artigos submetidos/publicados, os quais são resultados diretos deste trabalho é apresentada.

- Artigos publicados em anais de conferencia:

1. Atomatic Embryonic Stem Cell Detection and Counting Method in Fluorescence Microscopy Image, publicado nos anais da 6th International Symposium on Biomedical Imaging (ISBI'09), Boston - Massachusetts, E.U.A., ISSN:1945-7928, DOI:10.1109, volume 1, páginas 799-802, Junho de 2009.

2. Improved Automatic ES Cells Counting Method in Fluorescence Microscopy Images, publicado nos anais da 17th International Conference on Systems, Signals and Image Processing (IWSSIP'2010), volume 1, páginas 296-299, Rio de Janeiro, Brasil, Março de 2010.

- Artigos submetidos/publicados em Journals:

1. A Graph-mining algorithm for automatic detection and counting of embryonic stem cells in fluorescence microscopy image, artigo publicado em Integrated Computer-Aided Engineering, ISSN: 1069-2509(Print) 1875-8835(Online), DOI:10.3233/ICA2011-0359, volume 18, número 1, páginas 91-106, Janeiro de 2011.

2. Detecting Domes in Digital Images Using a Graph-mining Aprroach, submetido para Computer Vision and Image Understanding, Março de 2011. 


\section{Lista de Abreviaturas e Símbolos}

$\begin{array}{ll}\delta & \text { desvio-padrão da imagem } \\ \lambda & \text { diâmetro médio dos objetos da imagem } \\ \mu & \text { valor médio da imagem } \\ \varepsilon & \begin{array}{l}\text { tamanho do intervalo da partição do histograma da im- } \\ \text { agem }\end{array} \\ t & \text { threshold global simples } \\ x & \text { constante definida experimentalmente } \\ \text { CML } & \text { clusters de máximo locais } \\ \text { EB } & \text { embryoid body - corpo embrióide } \\ \text { EB cryosection } & \begin{array}{l}\text { células tronco provenientes de seções de corte em cor- } \\ \text { pos embrióides } \\ \text { ES cell }\end{array} \\ \text { MEF } & \begin{array}{l}\text { embryonic stem cell - célula tronco embrionária } \\ \text { murine embryonic fibroblasts - fibroblastos embrionários } \\ \text { mES }\end{array} \\ \text { mAG } & \begin{array}{l}\text { murinos } \\ \text { brionárias murinas }\end{array}\end{array}$


"Talvez eu venha a envelhecer rápido demais. Mas lutarei para que cada dia tenha valido a pena. Talvez eu sofra inúmeras desilusões no decorrer de minha vida. Mas farei que elas percam a importância diante dos gestos de amor que encontrei. Talvez eu não tenha forças para realizar todos os meus ideais. Mas jamais irei me considerar um derrotado. Talvez um dia o sol deixe de brilhar. Mas então irei me banhar na chuva. Talvez um dia eu sofra alguma injustiça. Mas jamais irei assumir o papel de vítima. Talvez eu seja enganado inúmeras vezes. Mas não deixarei de acreditar que em algum lugar alguém merece a minha confiança. Talvez algumas pessoas queiram o meu mal. Mas irei continuar plantando a semente da fraternidade por onde passar. Talvez eu fique triste ao concluir que não consigo seguir o ritmo da música. Mas então, farei com que a música siga o compasso dos meus passos. Talvez eu não aprenda todas as lições necessárias. Mas terei a consciência que os verdadeiros ensinamentos já estão gravados em minha alma. Talvez eu me deprima por não ser capaz de saber a letra daquela música. Mas ficarei feliz com as outras capacidades que possuo. Talvez eu não tenha motivos para grandes comemorações. Mas não deixarei de me alegrar com as pequenas conquistas. Talvez a vontade de abandonar tudo torne-se a minha companheira. Mas ao invés de fugir, irei correr atrás do que almejo. Talvez eu não seja exatamente quem gostaria de ser. Mas passarei a admirar quem sou. Porque no final saberei que, mesmo com incontáveis dúvidas, eu sou capaz de construir uma vida melhor. E se ainda não me convenci disso, é porque como diz aquele ditado: "Ainda não chegou o fim". Porque no final não haverá nenhum "talvez" e sim a certeza de que a minha vida valeu a pena e eu fiz o melhor que podia."

Aristóteles, . 